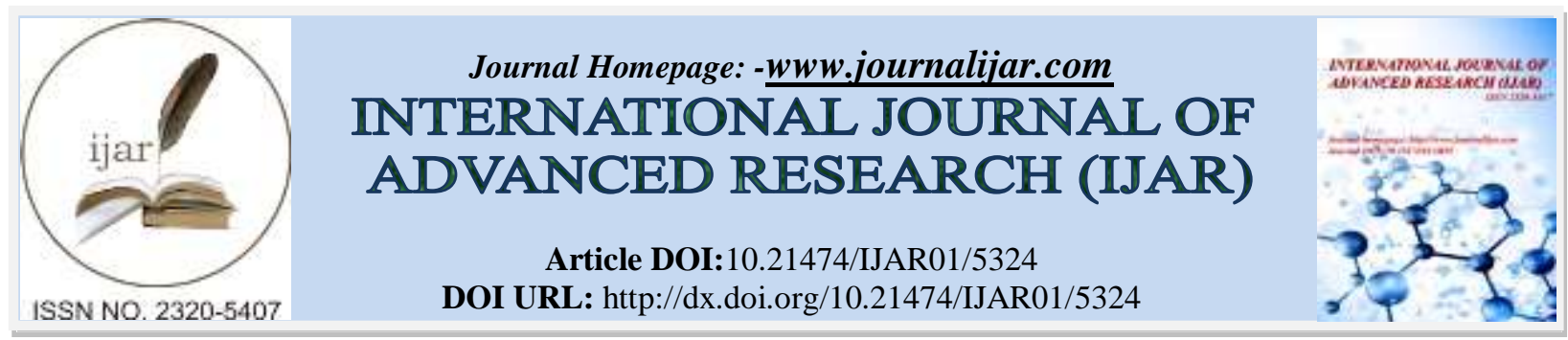

RESEARCH ARTICLE

\title{
THE COLOUR STABILITY OF THE NANOHYBRID COMPOSITE- EFFECTS OF THE IMMERSION MEDIA.
}

Dr. Suranjita Das ${ }^{1}$, Dr. Asim Bikash Maity ${ }^{2}$, Dr. Sanjit Lal Das ${ }^{3}$ and Dr. Pubali Sarkar ${ }^{4}$.

1. $3^{\text {rd }}$ year PGT, Department of Conservative Dentistry and Endodontics, Haldia Institute of Dental Sciences and Research, P.O. Balughata, Haldia, West Bengal.

2. Reader, Department of Conservative Dentistry and Endodontics, Haldia Institute of Dental Sciences and Research, P.O. Balughata, Haldia, West Bengal.

3. Professor, HOD, Department of Prosthodontics and Crown and Bridge, Haldia Institute of Dental Sciences and Research, P.O. Balughata, Haldia, West Bengal.

4. Lecturer, Department of Public Health Dentistry, Haldia Institute of Dental Sciences and Research, P.O. Balughata, Haldia, West Bengal.

\section{Manuscript Info}

Manuscript History

Received: 04 July 2017

Final Accepted: 06 August 2017

Published: September 2017

Key words:-

Color change, composite restorations, spectrophotometer.

\section{Abstract}

Aim: The colour stability of the nanohybrid composite- the effects of the immersion media.

Materials and method: 50 specimens of the material to be tested were prepared with the dimension of (10mm x $2 \mathrm{~mm}$ thickness) by mould then the specimens divided into five main groups according to the immersion media like tea, coffee, turmeric, cocacola, listerine. The specimens were evaluated after $24 \mathrm{hrs}$ and 7 days under spectrophotometer.

Results: The results showed that immersion of samples in staining solutions produce significant color change.

Conclusion: Turmeric solution has the maximum staining followed by coffee, tea, Coca cola, then Listerine.

Copy Right, IJAR, 2017,. All rights reserved.

\section{Introduction:-}

Dentists replace missing tooth or a part of the tooth structure by artificial materials. For any material to be used, it is of paramount importance that it fulfills four main criteria - strength, function, fit, and esthetics ${ }^{1}$. Resin-based composites are among the most frequently used dental materials for aesthetic restorations in dental practices due to their ability to bond to enamel and dentine, resemblance to tooth structures in color and mechanical properties, ease of chair-side applications and relatively low costs ${ }^{2}$. Shades of the restorative material are developed to fulfill the criteria of the natural shade of the teeth, food habits of the individuals and the geographical factors (example various minerals present in water). Manufacturers have introduced different shades for restorative materials, capable of fulfilling all the requirements for light sensitivity, depth or cure, color match and stability ${ }^{3}$. As a sequence to the introduction of nano-technology to the dental profession, a new class of dental resin-based composites has been developed in recent years. Nanoparticle resin-based composites - claim to combine the mechanical strength of hybrid resin-based composites and the superior aesthetic properties of microfill materials ${ }^{4}$. Color stability is an important parameter for modern resin-based filling materials. Several factors influence the color stability of contemporary light activated materials. These are the photoinitiator system, the resin matrix, the light-curing unit used for polymerization, and the irradiation times ${ }^{5}$. Discoloration of tooth-colored resin-based materials may be 
caused by several intrinsic and extrinsic factors. The intrinsic factors involve the discoloration of the resin material itself, such as the alteration of the resin matrix and of the interface of the matrix and the fillers. The resin matrix has been reported as being critical to color stability, and staining may be related to high resin content and water absorption ${ }^{6}$. Extrinsic factors for discoloration of resin-based composites include staining by adsorption or absorption of coloring agents from exogenous sources such as coffee, tea, turmeric, beverages and mouth rinses. The degree of discoloration from exogenous sources varies according to the oral hygiene, the eating-drinking and smoking habits of the patients ${ }^{6}$.

\section{Materials and methods:-}

Test specimens of the material to be studied were fabricated with dimension of (10 mm diameter x $2 \mathrm{~mm}$ thick). The mould was prepared from elastomeric impression materials like addition silicone and buttons. Buttons $(10 \mathrm{~mm} * 2 \mathrm{~mm})$ were pressed into the addition silicone and the buttons were taken after the material had already set. Thus the mould were prepared. Uncured resin composite samples were prepared by condensing them into a mould in two increments according to the manufacturer's instructions. After inserting the material into the mold, a polyester strip was pressed onto the surface of the mold with a glass plate in order to obtain a flat surface without bubble formation; excess material was extruded by pressing a glass plate onto the mold with a 500-g weight on top over the resin composite/matrix ensemble, producing specimens with a smooth flat surface. The weight was removed after $1 \mathrm{~min}$. The specimens were light polymerised ${ }^{7}$.
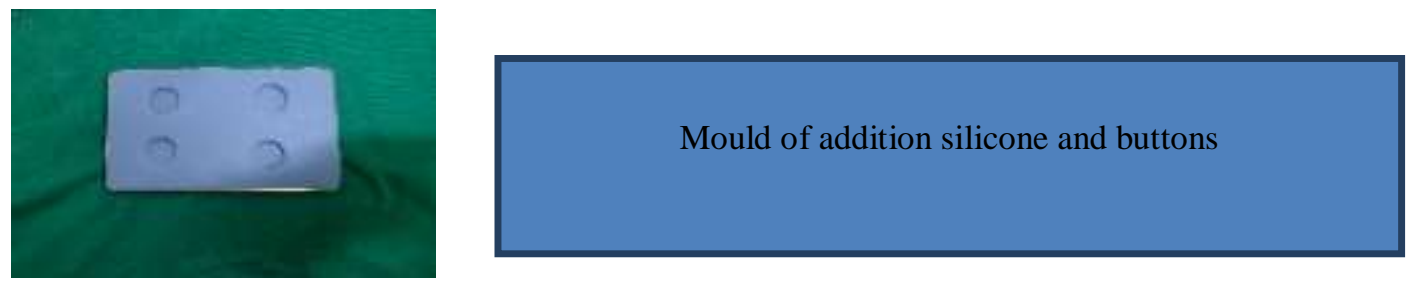

All specimens were polymerized by a LED (light emitting diode) device, whose power density is greater or equal to 1,000 Mw per square centimeter and it requires 10 seconds to cure $4 \mathrm{~mm}$ thickness material. The distance between the light source and the specimen was standardized by the use of a $1 \mathrm{~mm}$ glass slide in which the end of the curing light was in contact with the cover glass slide during the light polymerization process, the thickness and diameter of each test specimen was checked with a digital caliper.

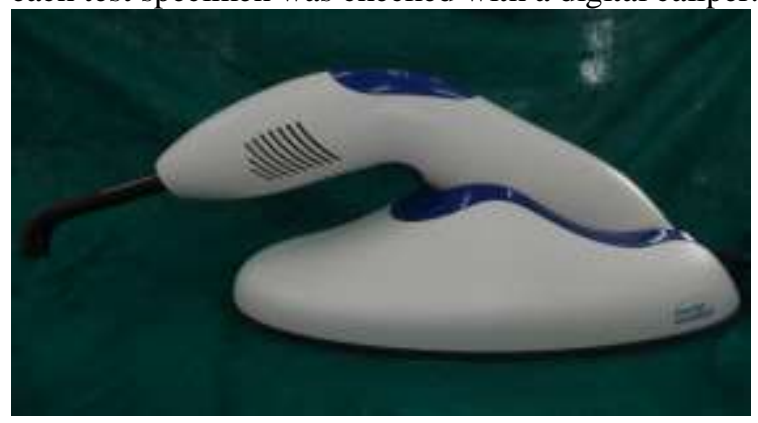

Led device

The samples were divided in 5 groups with 10 specimens each. The specimens had their color stability and luminosity evaluated at two immersion times (T0- $24 \mathrm{~h}$ of immersion in distilled water, T2 - after 7 days). The composite resin specimens were randomly subdivided into 5 groups: the control group was maintained in distilled water and the five experimental groups were submerged in selected beverages. Five specimens of each resin were chosen randomly and immersed in distilled water as control at $37^{\circ} \mathrm{C}$ for 24 hours. Following the first immersion cycle, all specimens were removed, rinsed under tap water, and blot-dried before color measurement. After initial measurement, the composite resin specimens were randomized into 5 groups (number=10) according to immersion media: coffee, tea, cola beverage turmeric and water (control solution). The coffee and tea solution was prepared by using $25 \mathrm{~g}$ of powder for $250 \mathrm{ml}$ of water, standardized and changed every day. The beverage used was Coca-Cola; the $\mathrm{pH}$ of the cola beverage was measured using $\mathrm{pH}$ indicator paper (around 2.5) and also changed every day. 


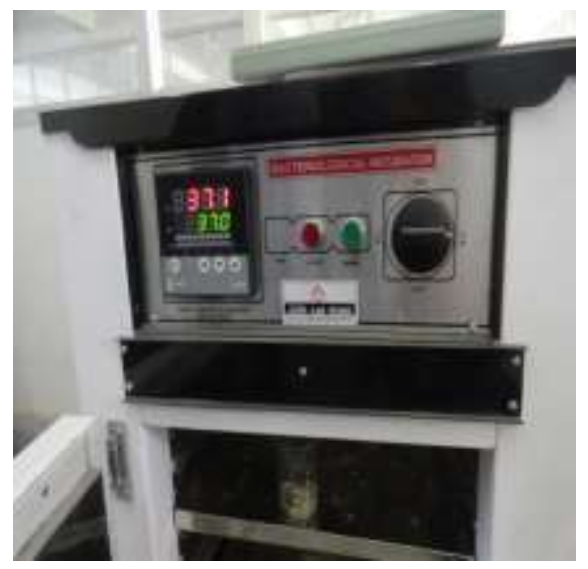

Incubator

Composition of the resin used in study: Commercial name- Tetric N-Ceram (Lot-S46213)

-Urethane dimethacrylate, Bis GMA (15\% by wt)

-EthoxylatedBis EMA (3.8 wt\%)

-Barium glass, ytterbium triflouride, mixed oxide,silicon dioxide (63.5 wt\%)

-Triehyleneglycoldimethacrylate

-Prepolymers (17 wt \%)

-Additives, stabilizers, catalysts, pigments $(0.7 \mathrm{wt} \%)$

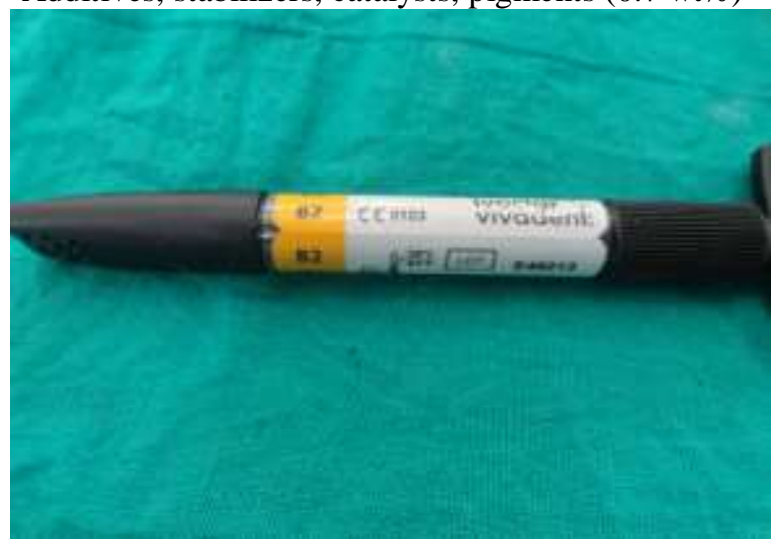

Composite used

The color of the specimens were measured with a spectrophotometer. The samples were dissolved in the chloroform and was tested with the spectrophotometer. 


\section{Results:-}

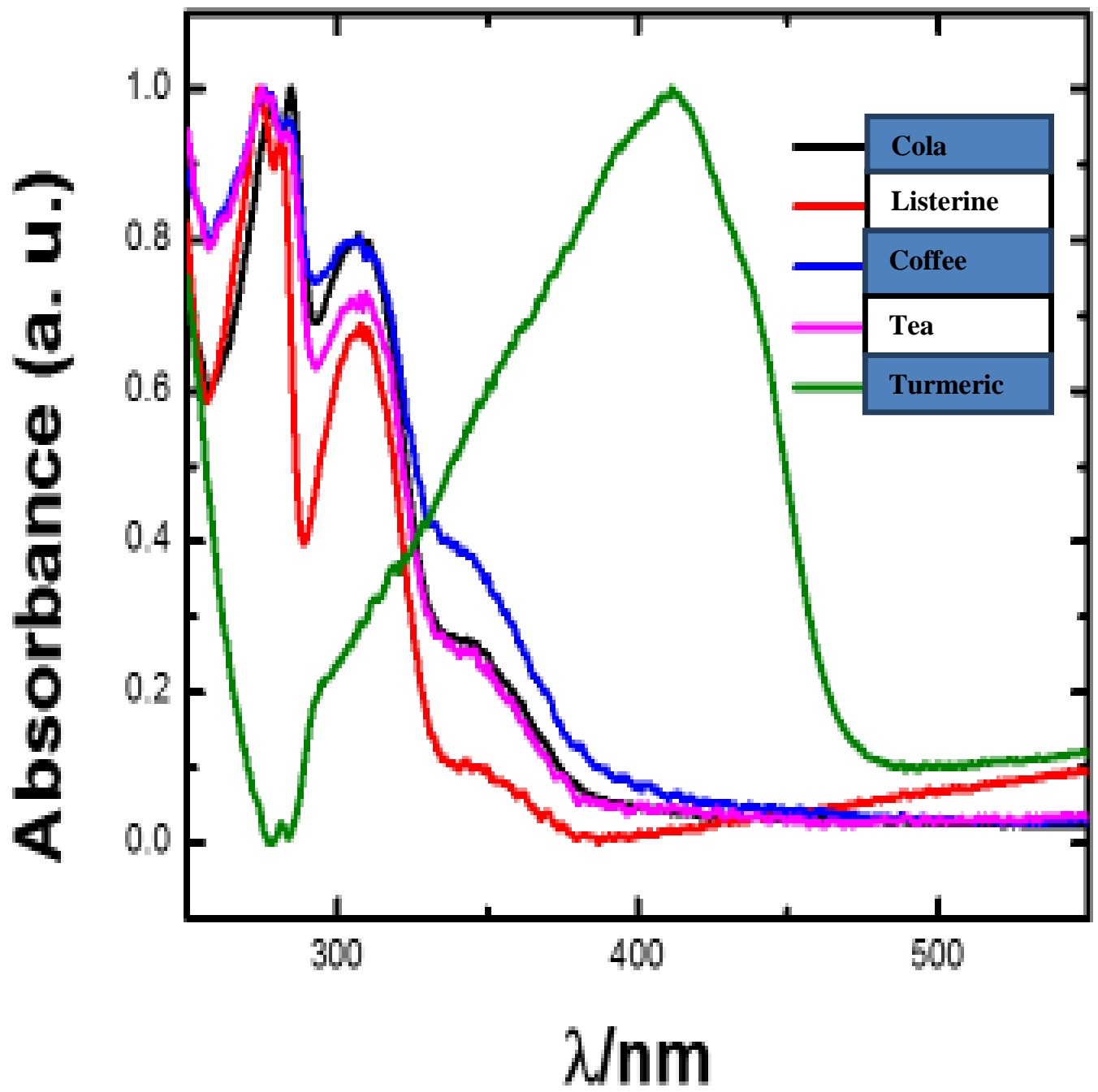

Absorption spectra comparision of different samples in chloroform solvent

\section{Discussion:-}

Color stability can be evaluated both visually and by specific instruments. The methodology used here is spectrophotometry ${ }^{8}$.

The effect of staining solutions on color changes of resin-based composites may be material-dependent. The staining susceptibility of a restorative material may be attributed to its resin matrix or filler type, the type of material had a significant role on stain resistance ${ }^{9}$.

Nano resin-based composites in comparison with microhybrid resin-based composites, these materials have been reported to have improved properties, such as, elastic modulus, mechanical strength and color stability. These improvements are achieved at low concentrations of the inorganic filler particles ${ }^{10-11}$.

Listerine has low $\mathrm{pH}$ (4.8) because it contains benzoic acid. These ingredients increase biodegradation of composite over time. This phenomenon is a complex process that may lead the resin-based composites polymer matrix to collapse, causing several problems such as filler polymer matrix debonding, release of residual monomers, wear and erosion caused by food, chewing and bacterial activity and causes staining ${ }^{12}$. 
Pires-de- Souza, et al. ${ }^{13}$ (2007), found that LED (light emitting diode) showed lower color changes for a hybrid resin, when compared to a conventional halogen unit. In addition, Soares, et al. ${ }^{14}$ (2007) observed chemical changes in the matrix of the resins polymerized by LED, which produced more staining of the composite when that device was compared to the halogen light source.

Camphoroquinone, which is the photoinitiator of Tetric N-Ceram, has a yellow color and its color changes when photoactivated, thus becoming "transparent". However, when the irradiation is not sufficient, a small amount of camphoroquinone remains inactive, causing a residual yellow in the final color of the composite resin ${ }^{15-17}$. Therefore, the light source is an important factor to be taken into account when an esthetic restoration is performed with composite resin.

The artificial saliva also promoted a slight color change in the specimens $(\Delta \mathrm{E}=1.73)$, classified as slightly perceptible ${ }^{18-19}$. The same result was obtained by Omata, et al. (2006), when comparing the color change of composite resin specimens immersed in distilled water and artificial saliva. The distilled water group did not undergo any color change.

According to Braden $\mathrm{M}$ et al, ${ }^{20}$ uptake of water by a resin composite is a diffusion-controlled process and occurs largely in resin matrix. Diffusion coefficients are generally lower in composites based on difunctionalmethacrylates (Systemp and Protemp) compared with methyl methacrylates (DPI) because of higher cross-linked nature of former leading to low water sorption

Turmeric was chosen as the media since it is widely used as an ingredient for cooking in the Bengal. The staining was maximum for turmeric solution followed by coffee and then tea (without milk).

These results are in concurrence with the study done by Stober $\mathrm{T}$ and Glide $\mathrm{H}^{21}$ who showed that turmeric solution and red wine caused the most severe discoloration $(\Delta \mathrm{E}>10)$ than tea, coffee and mouth rinse over 4 and 8 weeks. Scotti et $\mathrm{al}^{22}$ stated that the solution of saliva and coffee produced greater darkening than tea and artificial saliva at 10 and 30 days period. Yannikakis et al, ${ }^{23}$ used coffee and tea as medium and found that coffee-stained provisional resin restorative materials more than tea.

Conjugated diaryl hepnoids like curcumin are responsible for orange color and highest staining of turmeric solution. According to Hersek $\mathrm{N}$ et al, staining by tea and coffee is due to the presence of tannic acid colorant in them. Discoloration by tea is due to adsorption of polar colorants from tea whereas discoloration from coffee is due to both the surface adsorption and absorption of colorants. This might be the reason for coffee to be less color stable than tea.

\section{Conclusion:-}

Turmeric solution had the maximum staining potential followed by coffee, tea and Coca cola. Within the limitations of this in-vitro comparative study. Color stability of resin-based composites depend mainly on the material composition (the resin-based composites and mouthwashes). All staining solutions used have a potential to stain. Thus patient should follow the instructions of the practitioners after the restorations to avoid adsorption. This may minimize the stain of the teeth after restoration.

\section{References:-}

1. Singh K, Suvarna S, Agnihotri Y, Sahoo S, Kumar P., Color Stability of Aesthetic Restorative Materials after Exposure to Commonly Consumed Beverages: A Systematic Review of Literature. 2014: 2 (1): p.15-22.

2. Ren Y, Feng L, Serban D, Malmstrom H., Effects of Common Beverage Colorants on Color Stability of Dental Resin-based composites Resins: The Utility of AThermocycling Stain Challenge Model in Vitro. J. of dentistry 40S (2012)E48 - E56.

3. Puckett AD, Fitchie JG, Kirk PC, Gamblin J. Direct compositerestorative materials. Dent Clin North Am 2007;51:659-675.

4. Walker R, Burgess JO., Comparing Resin-Based Resin-basedcompositess. Compendium of Continuing Education in Dentistry.2004:25(6) 424, 426, 428.

5. Janda R, Roulet JF, Latta M, Steffin G, Rüttermann S. Color stability of resin-based filling materials after aging when cured with plasma or halogen light. Eur J Oral Sci. 2005;113:251-7. 
6. Topcu FT, Sahinkesen G, Yamanelk, Erdemir U, Aybala E.O, Ersahan S., Influence of Different Drinks on The Colour Stability of Dental Resin Resin-based compositess. European J. Of Dentistry January 2009: 3(1):50-56.

7. Ciccone-Nogueira, Borsatto, Souza-Zaroni\& Pereira Ramos., Microhardness of Resin-based composites Resins at Different Depths Varying the Post-Irradiation Time. J Appl Oral Science 2007: July/Aug: 15(4):305-309.

8. Campos MS, Roberti LF, Cruvine DR, Panzeri FC., Color Stability, Surface Roughness and Microhardness of Resin-based compositess Submitted to Mouthrinsing Action. J. Appl. Oral Science Bauru Mar. /Apr. 2012 : 20 (2).

9. Celik C, Yuzugullu B, Erkut S, Yamanel K., Effects of Mouth Rinses on Color Stability of Resin Resin-based compositess. European J. of Dentistry October 2008: 2: 247-253.

10. Lee Yk., Influence of Filler on the Difference between The Transmitted and ReflectedColors of Experimental Resin Resin-based compositess. Dent Mater. 2008; 24(9):1243-1247.

11. Ferracane J1., Hygroscopic and Hydrolytic Effects in Dental Polymer Networks. Dent Mater. 2006; 22(3):211222.

12. Villalta P, Lu H, Okte Z, Garcia-Godoy F, Powers Jm., Effects of Staining and Bleaching on Color Change of Dental Resin-based composites Resins. J. Prosthetic Dent 2006; 95:137-42.

13. Pires-de-Souza FC, Garcia LF, Hamida HM, Casemiro LA. Color stability of composites subjected to accelerated aging after curing using either a halogen or a Light Emitting Diode source. Braz Dent J. 2007;18:119-23

14. Soares LES, Cesar ICR, Santos CGC, Cardoso AL, Liporoni PCS, Munin E, et al. Influence of coffee on reflectance and chemistry of resin composite protected by surface sealant. Am J Dent. 2007;20:299-304.

15. Janda R, Roulet JF, Latta M, Steffin G, Rüttermann S. Color stability of resin-based filling materials after aging when cured with plasma or halogen light. Eur J Oral Sci. 2005;113:251-7.

16. Patel SB, Gordan VV, Barret AA, Shen C. The effect of surface finishing and storage solutions on the color stability of resin-based composites. J Am Dent Assoc. 2004;135:587-94.

17. Knezević A, Tarle Z, Meniga A, Sutalo J, Pichler G, Ristić M. Degree of conversion and temperature rise during polymerization of composite resin samples with blue diodes. J Oral Rehabil. 2001;28:586-91.

18. Mutlu-Sagesen L, Ergün G, Ozkan Y, Semiz M. Color stability of a dental composite after immersion in various media. Dent Mater J. 2005;24:382-90.

19. Buchalla W, Attin T, Hilgers RD, Hellwig E. The effect of water storage and light exposure on the color and translucency of a hybrid and a microfilled composite. J Prosthet Dent. 2002;87:264-70.

20. Braden M, Causton EE, Clarke RL. Diffusion of water in composite filling materials. J Dent Res 1976;55:7302.

21. Stober T, Gilde H, Lenz P. Color stability of highly filled composite resin materials for facings. Dent Mater 2001;17:87-94.

22. Scotti R, Mascellani SC, Forniti F. The in vitro color stability of acrylicresins for provisional restorations. Int J Prosthodont 1997;10:164-8.

23. Yannikakis SA, Zissis AJ, Polyzois GL. Color stability of provisional resin restorative materials. J Prosthet Dent 1998;80:533-9.

24. Um CM, Ruyter IE. Staining of resin based veneering materials with coffee and tea. Quintessence Int 1991;22:377-86. 